\title{
Book Review: Camilla Vásquez (2014). The Discourse of Online Consumer Reviews. London and New York: Bloomsbury Academic, pp. 194, 9781441196286.
}

\section{Bárbara Eizaga Rebollar ${ }^{1}$}

Universidad de Cádiz

Consumers' need to rate and review products, services or businesses online has led to a massive burgeoning of online reviews over the last decade, giving rise to a new computer-mediated communicative genre that has attracted the attention of many scholars. However, most research on computer-generated communication has revolved around the fields of marketing, business or computer sciences (Ganu et al., 2010; Hu et al., 2012; Jo \& Oh, 2011), leaving the linguistic and discourse perspectives unexplored. Thus, Camilla Vásquez's book fills this gap by presenting a thorough analysis of the common language and discourse features used in online consumer reviews.

As a Professor in the Department of World Languages at the University of South Florida, Camilla Vásquez's research interests range from the fields of discourse analysis, sociolinguistics, and pragmatics to those of cross-culturality in language teaching and the language of digital media.

The Discourse of Online Consumer Reviews is organized around six chapters, each of them finishing with a chapter conclusion section. The first one, An Introduction to Online Reviews, provides a general outline of the genre of online reviews, discussing its influence and economic impact on the business world. The first part of the chapter deals with the profile of the reviewer as a "prosumer" (p. 12), i.e. as a consumer who produces content for websites without remuneration, and the reasons for posting online reviews which

Universidad de Cádiz, Departamento de Filología Francesa e Inglesa, Facultad de Filosofla y

Letras, Bartolomé Llompart, s/n, 11003, Cádiz (Spain).

E-mail: barbara.eizaga@uca.es 
range from more altruistic reasons to reasons related to expressing frustration or enjoyment. The second one describes and compares the five websites used for collecting the 1,000 review texts, the 160 product types, and the 150,000 words which conform her corpus: Tripadvisor (for reviews of hotels), Amazon (for reviews of consumer goods), Netflix (for reviews of films), Epicurious (for reviews of recipes) and Yelp (for reviews of restaurants). In the following section, the author addresses her methodological framework for studying online reviews, which, as she points out, is descriptive, exploratory and eclectic, since she applies different approaches and techniques (from corpus linguistics, to narrative analysis and pragmatics) depending on the questions and topics under discussion. The chapter finishes with an overview of the issues she will examine in the following chapters of her book.

Chapter two, Evaluation and Stance in Describing Experience, explores the explicit and implicit evaluation strategies used by reviewers in different online review websites to express their opinion and to convince readers of their position. Even though the author acknowledges the achievements of sentiment analysis within computational linguistics to categorise online data as positive or negative opinions, she claims that evaluation depends very much upon the context, which determines whether a word, phrase or expression is "to be interpreted in positive or negative terms" (p. 33). Thus, she combines top-down and bottom-up approaches to her discourse analysis. The former are represented by some corpus linguistics tools - word frequency lists and concordance lines - to identify high-frequency patterns of evaluation at the word or phrase level. For instance, the adjective good does not always express positive evaluation while adverbs like definitely and again in constructions like will definitely make it again or back in can't wait to go/come/be back express the desire to repeat an experience as a form of positive assessment; on the other hand, stance adverbs like definitely, unfortunately or literally convey subjective information by highlighting a reviewer's commitment to a proposition, by emphasizing a positive or negative aspect of an experience or product, or by persuading readers of some proposition. The bottom-up or inductive approaches look at the discourse-level choices used by reviewers, namely the use of slang, interjections, rhetorical questions, declarative present-tense statements, references to the assessment of others, and justification of the star rating. These implicit forms of evaluation reveal the dependence of online reviews on specific practices of consumption in contemporary society, such as the never-ending search for perfection or expressions of satisfaction to present, past and future experiences as a way to get repeat customers.

Computer-mediated communication has provided means of self-expression for users allowing them to participate in the process of identity formation and to create online and offline identities (Davis, 2012; Walther et al., 2011). Chapter three, The Discursive Construction of Reviewer Identities, sheds some more light on how online identities are 
formed in different contexts. Her findings show that, in general, reviewers make references to traditional and lifestyle categories as markers of expertise and authenticity, proving that in most cases several aspects of their offline identity are carried over into their online identity. Further ways in which reviewers construct their expertise are by means of several situated identities, i.e. by explicitly or implicitly conveying information about their experience or inexperience in a particular area. In the author's opinion, all these cues help convince readers about the reviewer's trustworthiness, values and beliefs which can affect the final use of that information. An issue that is not dealt within this chapter but that could provide useful insights into the formation of online identities is the relation between the degree of consideration given to the imagined audience type that reviewers have in mind when posting online and the reviewer's self-presentation online (Litt and Hargittai, 2016).

In chapter four, Interacting with Others and with Other Texts: Involvement and Intertextuality, Vásquez discusses the various linguistic resources that reviewers use to interact with their readers or with other texts. Following an overview of involvement that the author defines as "a range of discursive resources that index some type of connection or interaction among participants - in this case, between authors of online reviews and the readers of those reviews" (p. 89), some of the most frequent involvement strategies used by online reviewers to engage their audience are considered, particularly secondperson address forms, imperatives, first-person plural forms, conventional speech act formulae (greetings, apologies, warnings, etc.), questions, discourse markers (interjections, emoticons, abbreviations, etc.) simulating or imagining conversations, and the addressing of business owners. The intertextuality section describes an array of intertextual practices used by reviewers to draw on some other texts such as referring to other reviewers, to the website, to other textual or discourse sources (Youtube, Wikipedia, etc.). The last part of the chapter examines the interaction between involvement and intertextuality in specific online reviews. Even though this chapter provides an excellent analysis of how reviewers interact and engage with their audiences, a study on the audience that reviewers imagine when constructing and posting their reviews, as suggested for the previous chapter, would probably shed some interesting data on the motivations underlying their involvement and intertextuality strategies, for instance their language use, cultural referents or style choice.

Chapter five, Digital Narratives of Personal Experience: Narrative Structures and Dimensions, hinges upon the form, features and function of narratives in online reviews following Labov's (1972) and Ochs and Capps's models (2001). Even though evaluation is an essential element of narratives, the author argues for a continuum of narrativity with highly narrative reviews at one end of the spectrum, and those mostly descriptive and evaluative with few, if any narrative elements at the other end of the continuum. Vásquez 
illustrates these ends of the continuum or "cline" of narrativity, as she calls it, with two review types - two opposing reviews of hotels and two other reviews of recipes applying the Labovian model, followed by some examples of exceptional narratives corresponding to film reviews and to restaurant reviews; a special analysis is devoted to a restaurant review which falls on the highly narrative end of the continuum. The chapter ends with an application of Ochs and Capps' five narrative dimensions to different prototypical product or service reviews on Amazon, which usually involve a combination of descriptive, evaluative and narrative modes of discourse. Nevertheless, the author states that narratives tend to be more common in negative than in positive reviews. The analysis of narratives reveals the vast number of reasons that reviewers choose to write reviews, ranging from sharing their personal experiences, to entertaining and to stating their values.

The final chapter assembles the main themes of the book offering a thorough analysis of how all these themes blend in a single review. The author then acknowledges some omissions and suggests some future directions for her work. Among the former she includes the topics of multiple modalities (i.e. visual images and videos) and follow-up comments to reviews; among the latter she mentions the combination of discourse analysis with other complementary approaches such as ethnography, politeness and impoliteness in online reviews, and reviews in languages other than English. The chapter ends with three broader social issues tangentially related to online reviews. First, Vásquez deals with the issue of authenticity, discussing different ways in which fake reviews might be spotted and different methods of authentication of the reviewer used by some websites like Yelp or Amazon. Second, the distribution of expertise and consumer empowerment brought by online reviews, since readers do not rely on experts to purchase products or services, but on peer authors sharing their own experiences about those products and services. This has, in the author's opinion, affected both positively and negatively consumer decision-making and businesses' reality in the sense that companies are beginning to manage their online reputation since any upset customer could have a negative impact on their business by posting a negative review. Finally, she considers some possible teaching implications derived from her work, specifically to encourage critical thinking, to reconcile different positions, and to understand the role discourse plays in online reviews.

One of the intentional omissions the author states in this last chapter is the multiple modality topic, which she justifies by claiming that most of the "online interactions remain primarily text based" (p. 160). While her claim is undeniable, it is also true that many of the online reviews include the posting of photographs (especially in the case of reviews of hotels, of restaurants, and of products) or videos (in the case of reviews of recipes) not only to "support, contribute to, and connect with, text-based reviews" (p. 
161), but also as a form of providing additional visual information to the text online getting a deeper understanding of the reviewer's opinion or experience, and thus for the reviewer to gain more credibility and authenticity from their audience, since, as the author herself claims, "the more we can be sure that the author of a review is writing from his/her genuine, direct experience [...] the more likely we will be to trust what we read" (p. 164). Hence, some research into the ways in which visual and text-based information interact in online reviews would be of much relevance to this study.

Regardless of the suggestions pointed out in previous paragraphs, this book has the merit of constituting an unprecedented study on the linguistic and discursive practices of consumers generating online texts. Using different discourse methods, Vásquez provides an extensive analysis of 1,000 online review texts, enabling readers to familiarise themselves with the most frequent discursive strategies of online reviews. On the whole, The Discourse of Online Consumer Reviews presents an innovative, accessible, and interdisciplinary approach to online reviews with many engaging examples that can be of much interest for scholars and students from many fields such as ESP, marketing, discourse analysis, and tourism among others.

\section{References}

Davis, K. (2012). 'Tensions of identity in a networked era: Young people's perspectives on the risks and rewards of online self-expression'. New Media \& Society, 14(4), 634-651.

Ganu, G., Marian, A. \& Elhadad, N. (2010). 'Ursa- User review structure analysis: understanding online reviewing trends'. DCS technical report $\mathrm{n}^{\circ}$. 668 <http://spidrursa.rutgers.edu/resources/TR_LRE.pdf> [22-12-2016].

Hu, N., Bose, I., Koh, N. S. \& Liu, L. (2012). 'Manipulation of online reviews: An analysis of rating, readability, and sentiments'. Decision Support Systems, 52(3), 674-684.

Jo, Y. \& Oh, A. (2011). 'Aspect and Sentiment Unification Model for Online Review Analysis'. Proceedings of ACM Conference on Web Search and Data Mining (WSDM-2011). <http://uilab.kaist.ac.kr/research/WSDM11/wsdm400-jo.pdf> [21-12-2016].

Labov, W. (1972). Language in the Inner City: Studies in the Black English Vernacular. Philadelphia: University of Pennsylvannia Press.

Litt, E. \& Hargittai, E. (2016). 'The Imagined Audience on Social Network Sites'. Social Media + Society, 2(1), 1-12.

Ochs, E. \& Capps, L. (2001). Living Narrative. Cambridge. MA: Harvard University Press.

Walther, J. B., Liang, Y. J., DeAndrea, D. C., Tong, S. T., Carr, C. T., Spottswood, E. L. \& AmichaiHamburger, Y. (2011). 'The Effect of Feedback on Identity Shift in Computer-Mediated 
Communication'. Media Psychology, 14(1), 1-26. 